\title{
ESTUDIOS
}

\section{El derecho a una buena administración pública en Chile}

\author{
The right to good administration in Chile
}

\author{
Izaskun Linazasoro Espinoza \\ Abogada, Chile
}

\begin{abstract}
RESUMEN Reconociendo su importancia, el derecho a una buena administración pública fue consagrado por primera vez en la Carta de Derechos Fundamentales de la Unión Europea. En Chile, si bien este derecho no ha sido reconocido de forma explícita, la sistematización de nuestro ordenamiento jurídico y del derecho administrativo en particular, permite reconocer los principios que lo conforman, los cuales han sido aplicados ampliamente por la jurisprudencia tanto administrativa como judicial. En este sentido, resulta interesante analizar dos sentencias recientes de la Corte Suprema que parecen reconocer, de forma casi explícita, este derecho a una buena administración.
\end{abstract}

PALABRAS CLAVE Administración, eficiencia, eficacia, transparencia, participación.

ABSTRACT Recognizing its importance, the right to good Administration was consecrated for the first time in the Charter of Fundamental Rights of the European Union. In Chile, this right has not been explicitly recognized, however, the systematization of our legal system and administrative law in particular, allows us to recognize the principles that comprise it, which have been widely applied by both administrative and judicial jurisprudence. In this sense, it is interesting to analyse two recent judgments of the Supreme Court, which seem to recognize, almost explicitly, this right to good Administration.

KEYWORDS Good administration, efficiency, effectiveness, transparency, participation

\section{Introducción}

Como bien señala el profesor Juli Ponce Solé «es cada vez más difícil hablar de la actuación administrativa como pura ejecución de la norma» (Ponce Solé, 2001: 36). Bajo esta premisa podemos advertir que los paradigmas clásicos que han definido al derecho administrativo han ido evolucionando, motivo por el cual ya no solo nos interesa la 
pregunta sobre el límite normativo del poder de actuación de la Administración, sino que también nos interesa estudiar bajo qué premisas podemos exigirle administrar mejor y más eficientemente los recursos públicos.

En este contexto actual, de cambios y evolución del derecho administrativo, surgen nuevas propuestas, como la Red Light y Green Light Theory (Harlow y Rawlings, 2009), que, poniendo acento tanto en las limitaciones como en la promoción de buenas prácticas administrativas, nos permiten entender de mejor forma la consagración del derecho a una buena administración pública, y sus distintas implicancias.

En efecto, desde esta perspectiva, podemos dar un nuevo entendimiento a una serie de derechos y principios, que se intentan articular como una garantía a la necesidad de exigir decisiones discrecionales de calidad y respetuosas del procedimiento administrativo, pero que también sean eficientes, eficaces, y consideren debidamente las observaciones de todos los interesados. Así, como veremos, en el marco del derecho europeo, se plantea la expresión «derecho a una buena administración pública» para estudiar desde una nueva perspectiva una serie de derechos, lo que está dando origen a una nueva línea dogmática y jurisprudencial, cuyas consecuencias se están comenzando a observar.

A su turno y en nuestro marco normativo, si bien en Chile no existen alusiones explícitas al derecho a una buena administración pública, la pretensión de este trabajo es encontrar las bases normativas que permitan su consagración. Junto con ello, pretendemos resaltar cómo la jurisprudencia judicial y administrativa (en particular la tercera sala de la Corte Suprema), se ha ido acercando al reconocimiento de este derecho, con considerandos bastante ilustrativos. Finalmente, intentaremos advertir algunas de las consecuencias de esta nueva locución, que creemos radica en la forma de entender el derecho administrativo moderno y la necesidad de actuar ante un mundo dinámico y variante. El derecho administrativo, en la actualidad, por el amplio objeto que intenta regular, necesita reglas de adaptabilidad que permitan una mejor y más eficiente Administración.

\section{Concepto de buena administración pública}

La noción de buena administración pública se ha ido desarrollando principalmente en los últimos veinte años, ${ }^{1}$ especialmente a partir de su consagración expresa en la Carta de Derechos Fundamentales de la Unión Europea del año 200o, también conocida como Carta de Niza, la cual lo define como un conjunto de derechos específicos que se pueden exigir a la Administración. ${ }^{2}$ Desde la doctrina, se han ensayado diferentes

1. El origen del concepto «buena administración» tiene un antecedente en el jurista francés Hauriou, quien señaló que «l'Administration ne doit pa se borner à être correcte e respectuese de la légalité; elle doit s'efforcer d’être habile» Traducción libre de la autora: La Administración no debe limitarse a ser correcta y respetuosa de la ley; ella debe esforzarse por ser hábil. Ya en el siglo XIX podemos decir que Hauroiu tenía una noción de buena administración, aunque se refería a ella desde una perspectiva más bien de «moralidad administrativa» (Hauriou, 1893).

2. Artículo 41 de la Carta de Niza: 
definiciones del derecho a una buena administración pública, desde «aquella que cumple con las funciones que le son propias en democracia» (Rodríguez-Arana, 2013: 18), pasando por quienes lo entienden como «una visión teórica [...] el objetivo mismo del Estado» (Pegoraro, 2011: 40), hasta aquellos que la consideran como «la adaptación equilibrada de los medios de la administración pública» (Bousta, 2010: 169). ${ }^{3}$ Esta última aproximación, de la francesa Rhita Bousta, resultará de especial relevancia para el análisis comparado que se realizará más adelante, ya que nos entrega ciertas luces de lo que en Chile se puede entender como buena administración.

La introducción de este derecho en el marco normativo de la Unión Europea y de sus principios, responde a un cambio de paradigmas en el derecho público. El estudio del derecho administrativo centrado en la limitación al poder estatal y el estudio de las potestades y privilegios de la Administración cede espacio a un paradigma distinto y moderno, centrado en los derechos del ciudadano, el bienestar, el bien común y el eficiente funcionamiento de las instituciones públicas. Este nuevo paradigma se manifiesta en los modelos modernos de administración pública, que se centran en las ideas de eficiencia y eficacia, y buena administración.

Así, la idea de buena administración intenta dejar de lado el clásico binomio del derecho administrativo potestad/derecho, para otorgarle la misma importancia tanto a la regla como a la gobernanza. En este sentido, es un principio rector para la Administración, que le permite guiar toda su actuación en pos del bien común y a la vez es un derecho para los ciudadanos, que permite exigir, como un derecho, que la Administración actúe conforme a los principios de la Red Light Theory, tal como lo entendieron Harlow y Rawlings (2009: 23). ${ }^{4}$

En definitiva, la consagración de este derecho responde a la modernización del derecho administrativo a nivel europeo y a la positivización de un derecho que ya estaba reconocido por la jurisprudencia europea (Viñuales Ferreiro, 2014: 329).

En una síntesis de lo que esta comprende, el art. 41 de la Carta de Niza enuncia que todos los ciudadanos cuentan con:

«DERECHO a una buena administración:

1. Toda persona tiene derecho a que las instituciones y órganos de la Unión traten sus asuntos imparcial y equitativamente y dentro de un plazo razonable.

2. Este derecho incluye en particular: el derecho de toda persona a ser oída antes de que se tome en contra suya una medida individual que le afecte desfavorablemente, el derecho de toda persona a acceder al expediente que le afecte, dentro del respeto de los intereses legítimos de la confidencialidad y del secreto profesional y comercial, la obligación que incumbe a la administración de motivar sus decisiones.

3. Toda persona tiene derecho a la reparación por la Comunidad de los daños causados por sus instituciones o sus agentes en el ejercicio de sus funciones, de conformidad con los principios generales comunes a los Derechos de los Estados miembros.

4. Toda persona podrá dirigirse a las instituciones de la Unión en una de las lenguas de los Tratados y deberá recibir una contestación en esa misma lengua».

3. Traducción libre. Original: «l'adaptation équilibrée des moyens de l'administration publique».

4. . Principios de eficiencia y eficacia, publicidad, participación, transparencia y probidad. 
- Derecho a audiencia;

- Derecho de acceso a los expedientes;

- Derecho a una resolución administrativa motivada;

- El derecho a reparación por los daños causados, y;

- El derecho a dirigirse a las instituciones en las lenguas oficiales de los tratados.

En este contexto normativo, dentro del sistema europeo de derechos humanos aparece una figura de especial relevancia: el Defensor del Pueblo europeo, también conocido como Ombudsman, que se configura como uno de los mecanismos de defensa de los derechos humanos en la Unión Europea, al que precisamente se le destaca «como garantía extrajurisdiccional por excelencia del derecho a la buena administración, dado que [...] se puede acudir a él para denunciar casos de mala administración provocados por las instituciones y organismos comunitarios» (Tomás Mallén, 2004: 222). La misma Carta de Niza consagra, a su vez, el derecho a petición, exigible tanto frente al Defensor del Pueblo como ante el Parlamento de la Unión Europea, reconocido como parte integrante de la condición de ciudadano de la Unión Europea (Tomás Mallén, 2004: 224).

A lo anterior Europa también suma el llamado «Código de Buena Conducta Administrativa», el cual pretende explicar - precisamente- lo que en la práctica significa el derecho a una buena administración pública (Mendes, 2009: párrafo 1). Si bien no tiene fuerza vinculante, se ha convertido en «el parámetro de conducta por excelencia para examinar si existe o no mala administración» (Carrillo Donaire, 2010: 1.142).

Francia, en particular, promulgó su "Code des relations entre le public et l'administration», en orden a facilitar el diálogo entre la Administración y los ciudadanos, fundado en la simplificación de relaciones, la transparencia y una mayor reacción por parte de la Administración ${ }^{5}$ (artículo 3, Ley 2013-1005). ${ }^{6}$ Este Código surge precisamente a raíz de la consagración del derecho a una buena administración pública: «[i]t is no coincidence, moreover, that in a context of general distrust towards public authorities (national or otherwise), the principle of/right to good administration is one of the factors of strength that European institutions as well are focusing on, a rediscovered instrument of democratic legitimation and accountability of public powers to citizens» (De Donno, 2017: 259).?

5.. Traducción libre de la autora del artículo 3.

6. Loi 2013-1005, «12 novembre 2013, habilitant le Gouvernement à simplifier les relations entre l'administration et les citoyens» o Ley 2013-1005 «12 noviembre 2013, autoriza al Gobierno a simplificar las relaciones entre la administración y los ciudadanos», publicada el 13 de noviembre de 2013 en el Journal Officiel de la République Française.

7. Nuestra traducción: «Esto no es coincidencia, además, que en un contexto de desconfianza hacia las autoridades públicas (nacionales o de otro tipo), el principio de/derecho a una buena administración es uno de los factores de fortaleza en la que las instituciones europeas también se están centrando, un instrumento redescubierto de legitimación democrática y rendición de cuentas de los poderes públicos a los ciudadanos». 
A partir de los derechos que reconoce explícitamente la Carta de Niza, la doctrina y la jurisprudencia europea han ido desarrollando una serie de principios que conforman el derecho a una buena administración pública, los que podemos resumir en: racionalidad, objetividad, transparencia, coordinación, eficiencia y eficacia (Cademartori Gamboa, 2009: 34).

El principio de racionalidad que rige el actuar de la Administración y de los órganos públicos impone el deber de «motivar los actos administrativos que dicten, además de actuar racionalmente en el uso de los recursos públicos» (Cademartori Gamboa, 2009: 36), de manera que se exige una actuación racional, lógica y al amparo de la legalidad vigente. Este deber, a su vez, se traduce en la prohibición de dictar actos arbitrarios. Este principio «debe servir de base a la entera actuación administrativa» (Rodríguez-Arana, 2014: 50).

La objetividad se encuentra estrictamente relacionada con la imparcialidad, lo que se traduce en que en el actuar de la Administración «el personal al servicio de la Administración deberá abstenerse de toda actuación arbitraria o que ocasione trato preferente por cualquier motivo» (Ponce Solé, 2001: 223).

La transparencia, por su parte, está relacionada con el acceso a la información de interés general. Es así como «el funcionamiento, actuación y estructura de la Administración ha de ser accesible a todos los ciudadanos, que pueden conocer la información generada por las administraciones públicas que realicen funciones de interés general» (Rodríguez-Arana, 2014: 51).

Respecto del principio de coordinación y cooperación "persigue la integración de la diversidad de las partes [...], evitando contradicciones y reduciendo disyunciones que, de subsistir, impedirán o dificultarán respectivamente la realidad del sistema» (Cademartori Gamboa, 2009: 48). A su vez, se señala que este principio promueve que «todos los órganos y entidades administrativos deben prestarse asistencia mutua y respetar el ejercicio de las respectivas competencias» (Rodríguez-Arana, 2014: 52).

El principio de eficiencia se relaciona con el comportamiento eficiente y económico de la Administración, en cuanto se ha señalado que «la eficiencia es «el parámetro que relaciona el coste de los recursos empleados con los objetivos alcanzados»» (Ponce Solé, 2001: 472). En definitiva, es el deber de actuar racionalmente en el uso de los recursos públicos.

Por otro lado, el profesor Ponce Solé rescata una definición genérica de eficacia: ««evoca básicamente la producción intencionada (con arreglo a un fin o causa) de una realidad (adecuada al fin) como resultado de la acción de un agente idóneo para obrar» aludiendo a «la producción real o efectiva de un efecto»» (2001: 472). En definitiva, es el principio por el cual «las autoridades buscarán que los procedimientos y las medidas adoptadas logren su finalidad» (Rodríguez-Arana, 2014: 50).

En definitiva, a través de este breve análisis es posible concluir que toda la construcción europea, en torno al artículo 41 de la Carta de Niza, ubica al derecho a una buena administración como un nuevo paradigma que no pone el foco en la juridicidad de las potestades públicas, sino en el cumplimiento de los estándares mínimos de actuación, 
con acento en la actuación imparcial, eficiente y razonable, estructurada en torno a un sistema de derechos de los ciudadanos.

\section{La buena administración pública en el ordenamiento jurídico chileno}

Caracterizado el derecho a una buena administración pública, parece relevante establecer si este derecho se encuentra consagrado - o no- dentro de nuestro ordenamiento jurídico.

Si bien nuestra Constitución Política de la República no reconoce el derecho a una buena administración pública de forma explícita, sí establece lo que podemos denominar el «núcleo de la buena administración» en sus bases generales.

Como señala el profesor Parejo Alfonso, la Administración y la ejecución administrativa se limita -como organización y actividad- al interés general (Parejo Alfonso, 2000: 249). ${ }^{8}$ En este sentido, no es difícil identificar a lo largo del capítulo primero de nuestra Constitución estándares de buena administración exigibles a todo el aparato estatal y los fines del Estado mismo. Cuando la Constitución Política de la República en su artículo primero establece que «el Estado está al servicio de la persona humana y su finalidad es promover el bien común», establece con claridad el fin que debe perseguir el Estado y el máximo estándar de buena administración: el bien común o interés general. Como señala el profesor Ponce Solé, «el entendimiento de la función administrativa como mera aplicación de normas jurídicas falla cuando el ordenamiento jurídico otorga a la Administración la misión de valorar cual sea la decisión más adecuada a los intereses generales» (2001: 72). En definitiva, la Constitución consagra las ideas de interés general, bien común y servicialidad, la cual ha sido desarrollada como «un «deber jurídico» que la Constitución impone al Estado, en razón de su finalidad y del carácter accidental e instrumental que posee, concebido este -además- de un modo específico, como medio de perfeccionamiento de las personas» (Soto Kloss, 2012: 147). En este sentido, la idea de buena administración se lee en plena armonía con los postulados del Estado social, democrático y de derecho, orientado al bien común y la maximización del bienestar.

La Constitución no solo se encuentra en armonía con el ideal de una buena administración, sino que adicionalmente, es posible encontrar una serie de derechos que forman parte de ella y cuya protección fue elevada a un rango superior y concebida como una garantía de las personas frente al Estado. Sin ir más lejos, los artículos 1, 5, 6, 7, 8, y 19 números 2, 3, 14 y 22 de la Constitución Política recogen principios tales como el principio de servicialidad, el de probidad, el de igualdad y prohibición de discriminación, el debido proceso, el derecho a audiencia y la motivación de las decisiones, el derecho de petición y el acceso a la información pública, otorgándoles incluso el carácter de derechos fundamentales.

8. . En este mismo sentido, el profesor Parejo Alfonso señaló en su visita a Chile, el año 2016, que la Administración es un mecanismo capital para la realización de fines (en relación al interés general), que requieren una acción sistemática y ordenada. 
Al mismo tiempo, la Constitución, en sus artículos 1 y 8, así como en su artículo 38 inciso segundo ( in perjuicio de otros), se refieren a los principios de control y de responsabilidad estatal.

Estableciendo, desde ya, que nuestra Constitución Política consagra los principios básicos que componen el núcleo de buena administración, ${ }^{9}$ resulta necesario, a su vez, realizar un análisis del bloque de legalidad que consagra los principios de buena administración. Para esto es interesante la utilización del esquema conceptual de la Red Light y Green Light Theory, introducido por Harlow y Rawlings (2009), ${ }^{10}$ para así clasificar los diversos principios legales.

En el plano de la Red Light Theory, respecto de las limitaciones a la acción estatal de la Administración encontramos los principios de legalidad, control y responsabilidad que desarrolla la Ley 18.575 .

Como bien sabemos, el principio de legalidad constituye tanto el presupuesto habilitante para la actuación de la Administración como el límite a su actuar. ${ }^{11}$ Este principio se encuentra consagrado en el artículo 2 de la Ley 18.575, Orgánica Constitucional de Bases Generales de Administración del Estado (LOCBGAE). ${ }^{12}$ Lo gravitante del principio de legalidad es el hecho de que es ella la que atribuye potestades a la Administración (Cordero Vega, 2015: 78).

Respecto del control, nuestra legislación establece una serie de medios a través de los cuales se puede asegurar el sometimiento de la actividad administrativa a los principios que la rigen y en general, al ordenamiento jurídico. En nuestra legislación se consagra el control que ejerce la Contraloría General de la República, pero también se reconocen tanto el control interno de los actos como el control judicial a través de recursos jurisdiccionales, consagrado en el artículo 9 de la LOCBGAE.

Por último, el principio de responsabilidad se encuentra establecido en el artículo 4 de la LOCBGAE que, tal como la regla constitucional, consagra la responsabilidad tanto de la Administración como la personal de los funcionarios. A su vez, se encuentra consagrado en clave de derecho de los administrados, en el artículo 17 letra g) de la Ley $\mathrm{N}^{\circ}$ 19.880, que establece las Bases de los Procedimientos Administrativos que rigen los actos de los órganos de la Administración del Estado (LBPA) cuando señala que «las personas, en sus relaciones con la Administración, tienen derecho a: g) exigir las responsabilidades de la administración pública y del personal a su servicio, cuando así corresponda legalmente».

En el plano ahora de la Green Light Theory, encontramos aquellos principios cuya

9. . En mayor profundidad, esta noción es desarrollada en Linazasoro (2018).

10. . Véase también Montt Oyarzún (2010).

11. Para mayor abundamiento véase Cordero Vega (2015: 76), en donde se trata precisamente la vinculación positiva y negativa.

12. Ley 18.575, artículo 2. «Los órganos de la Administración del Estado someterán su acción a la Constitución y a las leyes. Deberán actuar dentro del marco de su competencia y no tendrán más atribuciones que las que expresamente les ha conferido el ordenamiento jurídico». 
operatividad se da de cara a la sociedad y a la demanda de los ciudadanos, en particular, los principios de eficiencia y eficacia, publicidad, participación, probidad y transparencia.

El ideal de la Green Light Theory es precisamente la buena administración, sustentada en principios consagrados en nuestro ordenamiento, como lo son la eficiencia y eficacia (Ley 18.575, artículo 3), la publicidad (Ley 18.575, artículo 3, artículo 11 bis incisos tercero y cuarto; Ley 19.880, artículo 16), la participación, probidad y transparencia. Por ejemplo, en materia regulatoria y con especial énfasis en el derecho ambiental (Mirosevic Verdugo, 2011: 285), la participación ciudadana ha cobrado un importante rol en la gestión pública en cuanto mecanismo tanto como un derecho que permite: mejorar las decisiones públicas, la expresión de intereses diversos, la solución temprana de conflictos, fomentar y desarrollar el principio de cooperación, etcétera. Pero, principalmente, la participación dota a las decisiones de legitimidad. El problema que trae consigo el implementar esta técnica regulatoria participativa es la necesidad de aclarar que no es la participación per se la que dota de legitimidad a un acto administrativo, sino una participación ciudadana bien hecha, cumpliendo precisamente con los estándares de buena administración. Es así como podemos ver que incluso dentro de un procedimiento administrativo de participación, los mecanismos utilizados dentro de él deben cumplir con las exigencias de buena administración. Actualmente, la participación ciudadana en espacios, como el Sistema de Evaluación de Impacto Ambiental, es precisamente criticada por no cumplir con estos criterios, específicamente, por los estrechos y tardíos espacios de participación disponibles y por el «déficit de capacidades tanto de las comunidades y otros actores para tomar parte en procesos de participación, como de los organismos públicos para diseñarlos y conducirlos» (Durán y otros, 2016: 27-30).

Debemos advertir que el que nuestro ordenamiento jurídico esté consagrando y desarrollando estos principios y derechos fundamentales de la mano con la jurisprudencia, no significa un abandono de los clásicos principios de la Red Light Theory. Como señala el profesor Montt Oyarzún, «no se trata de retroceder a un Estado de policía desvinculado de la legalidad y del control jurídico, sino centrar la atención en la gestión y el servicio público» (2010: 11). Siguiendo esta línea, es fundamental para el derecho a una buena administración pública desarrollar los principios integrantes de la Green Light Theory, ya que «su operatividad primaria se da de cara a la sociedad y sus problemas» (2010: 11) son principios que están en estrecha relación con las garantías de las personas frente a la Administración.

Siguiendo la lógica de la Green Light Theory, cabe destacar que las normas de probidad y transparencia han jugado un papel importante en el desarrollo de estos principios.

En nuestro medio, resulta relevante la reforma legal de la Ley 19.653 del año 1999, también conocida como Ley de Probidad, que introdujo modificaciones a la Ley 18.575. El texto del actual artículo 55 de la LOCBGAE, que establece que «el interés general exige el empleo de medios idóneos de diagnóstico, decisión y control, para concretar, dentro del orden jurídico, una gestión eficiente y eficaz», no dista mucho de la definición que nos entrega Rhita Bousta sobre buena administración, que -recordemos- la 
considera como «la adaptación equilibrada de los medios de la Administración» (2010: 169). Esta definición de interés general no precisa qué se entiende por interés general sino cuáles son los medios para alcanzarlos. Y estos «medios» serían precisamente la idea de buena administración. Así mismo lo señala Bousta respecto de la definición de buena administración, cuando explicita que «la notion de bonne administration a trait, dans son essence, aux moyens et non au but de l'administration» (2010: 169). ${ }^{13}$

Podemos concluir entonces que la definición de buena administración se relaciona con los medios que posee la administración pública y sobre cómo debe emplearlos y que, respecto a este punto, nuestra legislación ya nos entrega una idea concreta y explícita de la misma, sobre la base del concepto de interés general. Esto es concordante con parte de la doctrina francesa (Bousta, 2010; Mendes, 2009), en tanto desarrolla la noción de buena administración - en su esencia - relacionada a los medios y no al propósito de la Administración, el cual termina siendo el interés general. Así, podríamos afirmar que el interés general en nuestra legislación es el deber de buena administración, ya que el artículo 55 de la LOCBGAE es plenamente concordante con la definición que la francesa Bousta nos entrega sobre la buena administración.

Ahora, continuando con el análisis del bloque de legalidad, y particularmente el relativo a las normas de probidad, a partir de las reformas introducidas desde el año 1999, cabe destacar que en enero de 2016 se promulgó la Ley 20.880 sobre Probidad en la Función Pública y Prevención de los Conflictos de Intereses, luego de cinco años de tramitación. Esta ley regula la práctica de la función pública desde el principio de probidad, con el objeto de prevenir los conflictos de interés. Entre otros temas, se encarga de establecer la obligación de declarar intereses y patrimonio, que dé cuenta de dónde permanecen los intereses de las autoridades y funcionarios, y a cuánto asciende su patrimonio.

Dentro del mismo contexto en que se desarrolla la Ley 20.88o, la elaboración de los «Códigos de Ética de la Función Pública» es una de las medidas administrativas contempladas en la Agenda de Transparencia y Probidad para la Política y los Negocios 136, presentadas por la Presidenta Bachelet el 11 de mayo de 2015. Esta iniciativa busca la sistematización de los valores y las conductas que se esperan dentro del buen ejercicio de las funciones públicas, para a su vez promoverlas y contar con un marco común.

En materia de transparencia, es necesario señalar que Chile cuenta con la Ley 20.285 sobre acceso a la información pública. Esta ley se caracteriza por (Cordero Vega, 2015: 114):

- Disponer de un concepto amplio de información pública;

- Consagrar la obligación llamada de «Transparencia Activa», información que debe estar permanentemente disponible;

13. Traducción libre de la autora: «El concepto de buena administración es esencialmente el medio y no el objetivo de la administración». 
- Establecer las causales de reserva o secreto que están taxativamente enumeradas en la ley;

- Establecer principios esenciales a la hora de interpretar la ley;

- Consagrar un órgano encargado de fiscalizar su cumplimiento: el Consejo para la Transparencia; $y$

- Si se es negada la información, reconoce igualmente un derecho a solicitar amparo de acceso a la información.

Con lo anterior, es posible advertir que los derechos y principios de buena administración, están consagrados en nuestro ordenamiento jurídico, aunque de forma dispersa. Pero lo cierto es que contamos con esta base normativa que permite adoptar la lógica de una buena administración. Más allá de su falta de sistematicidad, lo relevante es que los principios básicos para consagrar este derecho existen, y es posible aplicarlos conjunta y coordinadamente, como pareciera estar haciéndolo - de forma recientenuestra Corte Suprema, según detallaremos más adelante.

Ahora bien, la diferencia con el sistema europeo radica en que este, a través de la sistematización de sus principios, realiza un análisis y otorga una aplicación colectiva a esta serie derechos. A ello se suma que, bajo una misma voz, lo visibilizan con la promulgación de códigos de buena conducta, o de relaciones entre lo público y la Administración, así como también con el establecimiento de un Defensor del Pueblo encargado de su tutela, como hemos visto.

\section{Manifestaciones jurisprudenciales del derecho a una buena administración pública}

En Chile, tanto el Tribunal Constitucional como la Corte Suprema y la Contraloría General de la República han aplicado, a través de los años, los principios que conforman el derecho a una buena administración pública.

A modo de ejemplo, nuestra jurisprudencia ha consagrado el principio de debido proceso administrativo. El Tribunal Constitucional ha señalado que:

la Ley 19.880 de Bases de los Procedimientos Administrativos [...] establece un verdadero debido proceso administrativo, en ejecución del mandato del artículo 63 numeral 18 de la Constitución, pues permite oportuna y eficazmente al administrado presentar sus alegatos y discutir las afirmaciones hechas por la Administración (artículos 10, 17 y 20), presentar prueba e impugnarla (artículos 35 y 36), que su caso sea resuelto objetivamente (artículos 11 y 12), conocer en plazo oportuno una resolución final (artículos 7,8 , 9, 13, 16, 18, 24, 27, 41, 64 y 65) y, en su caso, impugnarla (artículos 15, 59 y 60) (Sentencia del Tribunal Constitucional, rol 1.413-2009, 2010: considerando vigésimo séptimo).

La jurisprudencia en materia del principio de eficiencia administrativa se ha centrado en el deber del Estado de velar por la eficiente e idónea administración de los medios públicos y por el debido cumplimiento de la función pública, señalando que: 
de tal suerte que habiendo el Fisco proporcionado los medios para la pronta realización de una faena cuyo obligado no había cumplido en el tiempo dispuesto, en pro de esa misma eficiencia, debe ejercer las acciones para recuperar los fondos públicos invertidos. Admitir lo contrario implicaría dejar en la indefensión a la Administración y favorecer el incumplimiento de las obligaciones por parte de los administrados, lo que repugna a la eficacia del derecho (Sentencia de la Corte Suprema, rol 46.494-2016, 2017: considerando décimo quinto).

La eficiencia se relaciona también con el principio de celeridad, respecto del cual la Corte Suprema ha señalado que su contravención produce una «ineficacia en la tardanza administrativa» y que «la tardanza inexcusable de la Tesorería General de la República ha excedido todo límite de razonabilidad» (Sentencia de la Corte Suprema, rol 7.284-2009, 2010).

Respecto del principio de eficacia de los actos administrativos, podemos señalar que la Contraloría General de la República lo ha caracterizado como una manifestación de la soberanía, señalando que los actos administrativos obligan «a su cumplimiento mediante acción de oficio o de ejecución forzosa, lo que emana de los artículos 5, 6 inciso segundo y artículo. 32 numeral 6 de la Carta Fundamental, ya que el cumplimiento de la función administrativa, a través de sus actos, constituye el ejercicio de la soberanía conferido a los órganos estatales, obligando por ello a todos» (Dictamen 2.196, 1993).

A su vez, se ha consagrado el principio de objetividad e imparcialidad, cuando la Contraloría General de la República ha señalado que «la imparcialidad de la autoridad llamada a intervenir en la evaluación de un empleado, es un elemento esencial para garantizar la transparencia y objetividad del proceso» (Dictamen 63.579, 2015).

Respecto de la probidad administrativa, hay que destacar que existen múltiples dictámenes de la Contraloría que se refieren a este principio, entre ellos cabe destacar aquellos que se refieren específicamente a las conductas que contravienen especialmente este principio como:

el hecho de que un servidor intervenga, en razón de sus funciones, en asuntos en que tenga interés personal o en la adopción de decisiones en que exista cualquier circunstancia que le reste imparcialidad, imperativos que, en similares términos, se consultan en el artículo 78 de la Ley 18.834 sobre Estatuto Administrativo. Como puede advertirse, el objetivo de la indicada normativa no es otro que el de impedir que intervengan no solo en la resolución sino que también en el examen o estudio de determinados asuntos o materias, aquellos funcionarios que puedan verse afectados por un conflicto de intereses en el ejercicio de su empleo o función, en virtud de circunstancias que objetivamente puedan alterar la imparcialidad con que estos deben desempeñarse» (Dictamen 46.002, 2001).

Respecto de los principios de transparencia y publicidad, la Corte Suprema ha señalado que «el procedimiento administrativo debe realizarse con transparencia, de manera que permita y promueva el conocimiento, contenido y fundamentaciones de las decisiones que se adopten en él». En este mismo fallo, se destaca la importancia y 
relación de la transparencia y publicidad, con el principio de motivación de los actos administrativos, estableciendo que «es un requisito sustancial la expresión del motivo o fundamento por el cual se adopta una determinación por la autoridad administrativa, pues su exigencia ha sido puesta como condición mínima de racionalidad» (Sentencia de la Corte Suprema, rol 92.957-2016, 2017).

En términos generales, es necesario destacar también que en numerosos dictámenes la Contraloría General de la República ha hablado de «medidas de buena administración» en relación a decisiones adoptadas por la autoridad relativas a la función pública: en materia de distribución de funciones (Dictamen 57.163, 2014), ${ }^{14}$ de encomendación de funciones (Dictamen 52.322, 2013) y en materia de asignación de funciones propias de planta (Dictamen 50.502, 2013). Sin embargo, en estos dictámenes no se entiende, propiamente tal, consagrado el derecho a una buena administración pública como lo entiende la Unión Europea.

De forma reciente, la Corte Suprema ha dictado una serie de fallos que consagran casi explícitamente el derecho a una buena administración pública. Tal es el caso de la sentencia de 8 de enero de 2018, en la que conociendo de una reclamación de ilegalidad por una multa impuesta por la SEC señala que del artículo 3 del DFL 1 del año 2000 , se desprende que:

Los órganos de la Administración se hallan regidos por un conjunto de principios que los obligan, en el desempeño de sus labores, a obrar, entre otras exigencias, con la mayor responsabilidad, eficiencia, probidad y transparencia, de manera que su actividad no puede entenderse caracterizada por un cariz de pasividad o indiferencia, sino que, por el contrario, en su desempeño tales entidades han de impulsar el avance de los procedimientos que deben conocer, deben emplear con eficiencia los recursos que han sido puestos a su disposición y deben someter sus decisiones a la revisión de sus superiores (Sentencia de la Corte Suprema, rol 38.817-2017, 2018: considerando tercero).

De esta forma, la Corte Suprema reconoce la consagración de los principios que conforman el derecho a una buena administración pública y les da una expresión práctica concreta. Pero no se queda solamente ahí, ya que agrega que:

De tales predicamentos se desprende, como es evidente, un mandato que los engloba y que obliga a la Administración a ejercer sus facultades y a cumplir sus deberes de manera que los mismos se vean plenamente satisfechos (Sentencia de la Corte Suprema, rol 38.817-2017, 2018: considerando tercero).

En este extracto parece evidente que lo que hace la Corte Suprema es reconocer que existe un mandato que engloba los principios antes expuestos y este mandato genérico, a mi juicio, no puede ser otro que el derecho a una buena administración pública. La Corte Suprema, a través de este fallo, reconoce de forma casi explícita este

14. . En el mismo sentido Dictamen 34.322 (2011). 
derecho a una buena administración pública y además señala que este derecho obliga a la Administración a actuar y a ejercer sus deberes, empleando con eficiencia los recursos, revisando sus decisiones y promoviendo el avance de los procedimientos administrativos.

Por otra parte, en diciembre de 2017 la Corte Suprema, en dos sentencias sobre gestión de riesgos por parte de la autoridad administrativa (Sentencias de la Corte Suprema, roles 34.536-2013, 2017 y 37.834-2017, 2017), crea un estándar para adoptar decisiones administrativas complejas pero efectivas y que minimicen riesgos para la población. Con base en principios de buena administración, crea este test de idoneidad para la adopción de decisiones administrativas integradas (Cordero Vega, 2017). En efecto, la Corte Suprema señala que los organismos administrativos, al adoptar decisiones de este tipo, deben respetar los principios de:

- Proporcionalidad;

- Oportunidad;

- Coordinación;

- Unidad de acción;y

- Optimización del uso de los medios.

Estas dos sentencias manifiestan la dificultad que ha tenido la aplicación del principio de coordinación en el derecho público actual, producto de la «agencificación» del Estado, ya que «a pesar de ser un principio jurídico clásicamente establecido a nivel normativo [lo sigue siendo hasta hoy], uno de los principales desafíos que deben enfrentar las Administraciones Públicas modernas para lograr niveles razonables de gobernabilidad» (Cordero Vega, 2017).

Con lo anterior, podemos advertir entonces que, si bien nuestro ordenamiento jurídico no consagra de forma explícita el derecho a una buena administración pública, en la práctica los criterios jurisprudenciales son los mismos y las formas de decidir caso a caso no varían en el fondo. Tanto el sistema de la Unión Europea como nuestro derecho administrativo nacional protegen los principios que conforman el derecho a una buena administración pública.

\section{Conclusiones}

El derecho a una buena administración pública responde a una época de cambios en el derecho administrativo. En primer lugar, responde a una alteración de paradigma que muestra un tránsito desde las potestades y privilegios de la Administración a los derechos de los ciudadanos (Ferrada Bórquez, 2007). Pero también responde a lo que se ha llamado «el movimiento de reforma del derecho administrativo» (Cordero Vega, 2018), que -como señala el profesor Cordero Vega- «entiende a esta disciplina desde la perspectiva de la dirección, en donde el derecho administrativo proporciona un pro- 
grama de conducta y no un simple modelo de control, como lo entendió el viejo derecho público» (2018).15

El antiguo paradigma del derecho administrativo no responde a las necesidades modernas ni da respuestas completas a problemas públicos complejos, «la denominada transformación del derecho administrativo en uno de regulación adaptativa, hace sencillamente imposible concebir un sistema reducido a la ecuación control-derechos» (Cordero Vega, 2018). Hoy en día, la única manera de dar seguridad jurídica es teniendo normas que permitan la adaptación.

Es importante entender que cuando el objeto a regular es dinámico y variante, el tener reglas invariables no genera seguridad jurídica, ya que el resultado puede llegar a ser igual de incierto - pero incontrolable - que teniendo reglas que permitan la adaptabilidad según el objeto a regular. En este mundo, dinámico y veloz, la pretensión de reglas estables es imposible. Es así como el derecho a una buena administración pública surge como un puente entre la teoría legal y la realidad, dinámica y variante. El derecho a una buena administración pública intenta dar una respuesta a la interrogante respecto a

cómo debemos comprender sistemas complejos como la regulación ambiental, el urbanismo o los mercados financieros, en donde el derecho público necesita reglas de habilitación para adecuaciones prospectivas (la necesidad de dar soluciones para resolver interrogantes futuras, sensibles y de resultados inciertos), porque es en la interacción de las personas en la ciudad, las actividades económicas con la variabilidad de los ecosistemas y las dinámicas aceleradas de los agentes financieros, en donde el derecho administrativo tiene una presión para dar respuestas oportunas, manteniendo los compromisos constitucionales elementales de una democracia (Cordero Vega, 2018).

El derecho administrativo tiene hoy un desafío importante: hacerse cargo de las interacciones y resultados que generan las decisiones públicas. Y en este sentido, el derecho a una buena administración pública, ya sea como derecho o como principio, establece una serie de directrices u orientaciones que permite a los órganos del Estado tomar decisiones dinámicas, pero a su vez, manteniendo un lazo con el ordenamiento jurídico.

Este desafío tiene que ver con la forma de afrontar, desde otras perspectivas, ${ }^{16} \mathrm{el} \mathrm{ob}-$ jeto de estudio del derecho administrativo: un objeto múltiple, dinámico y variante. Así mismo parece entenderlo parte de la doctrina francesa cuando analizan las dimensiones del derecho a una buena administración: «il rappelle que l'administration devrait s'efforcer de promouvoir certain aspects de la bonne pratique administrative qui vont au-delà de la sphère juridique au sens strict» (Mendes, 2009: 571). ${ }^{17}$

15. . En referencia a Schmidt-Assmann (2003), Wahl (2013) y Parejo Alfonso (2000).

16. . En este sentido, parece necesario afrontar esta nueva forma de ver el derecho público también desde las ciencias sociales.

17. Traducción libre de la autora: «recuerda que la administración debe esforzarse por promover ciertos aspectos de las buenas prácticas administrativas que van más allá de la esfera jurídica en sentido estricto». 
Si tenemos claridad en esto, será necesario sincerar el hecho de que hay cosas que la administración pública puede hacer sin una regla y admitir cierto margen de error. Claro está que los factores que influyan y las reglas de competencia dependerán del sector de referencia en particular, ya que precisamente el derecho a una buena administración evoca la idea de dinamismo y adaptabilidad, según ha de aplicarse a uno u otro sector. En definitiva, el derecho a una buena administración pública lo podemos entender como el puente que une la toma de decisiones dinámicas y eficientes con el ordenamiento jurídico, otorgándoles legitimidad. Y la importancia de su eventual consagración viene de la mano con dejar de lado la pretensión de reglas estrictas, que parece ya nada tiene que ver con el derecho administrativo moderno, en la actualidad compleja y cambiante.

\section{Referencias}

Bousta, Rhita (2010). Essai sur la notion de Bonne Administration en droit public. Paris: L'Harmattan.

Cademartori Gamboa, David (2009). «Buena administración y procedimientos de selección de contratistas: análisis de mecanismos jurídicos e informativos para alcanzar la eficiencia en las licitaciones públicas». Tesis doctoral. Universidad de Salamanca.

Carrillo Donaire, Juan Antonio (2010). «Buena administración ¿un principio, un mandato o un derecho subjetivo?». En Juan Alfonso Santa María Pastor (2010) Los principios jurídicos del derecho administrativo. España: La Ley.

Cordero Vega, Luis (2015). Lecciones de Derecho Administrativo. Santiago: Legal Publishing.

-. (2017). «El test de idoneidad para adoptar decisiones administrativas integradas». $E l$ Mercurio Legal, 28 de diciembre de 2017.

-. (2018). «El problema de identidad del Derecho Administrativo chileno». El Mercurio Legal, 27 de febrero de 2018.

De Donno, Marcia (2017). «The French Conde «Des relations entre le public et l'administration», a new european era for administrative procedure?». Italian Journal of Public Law, 9 (2): 220-260

Durán, Valentina, Guillermo González, Emilia Ríos, Claudia Sepúlveda, Lorena Schmitt y Rodrigo Wagner (2016). «Del conflicto al diálogo: cómo avanzar hacia un sistema eficiente de decisiones ambientales participativas». En: Informe de Políticas Públicas, 8. Espacio Público.

FERrada BóRquez, Juan Carlos (2007). «Potestades y privilegios de la administración pública en el régimen administrativo chileno». Revista de Derecho, 20 (2): 69-94.

Harlow, Carol y Richard Rawlings (2009). Law and Administration. Londres: Cambridge University Press.

Hauriou, Maurice (1893). Précis de Droit Administratif. Paris: Librairie du Recueil Général des Lois et Arrêts et du Journal du Palais. 
LiNAZASORO EsPINOZA, Izaskun (2018). «El derecho a una buena administración pública. Cambios de paradigmas en el Derecho Administrativo chileno: de las potestades y privilegios a los derechos ciudadanos». Barcelona: TranJus Universitat de Barcelona.

Mendes, Joana (2009). «La bonne administration en droit communautaire et le code européen de bonne conduite administrative». Revue française d'administration publique, 3 (131): 555-571.

Mirosevic Verdugo, Camilo (2011). «La participación ciudadana en el procedimiento de evaluación de impacto ambiental y las reformas introducidas por la Ley 20.417». Revista de Derecho de la Pontificia Universidad Católica de Valparaíso, 36: 281 - 323.

MonTt Oyarzún, Santiago (2010). «Autonomía y responsividad: dos expresiones de la vocación juridificadora del Derecho Administrativo y sus principios fundamentales». Santiago: Centro de Regulación y Competencia (REGCOM).

Parejo Alfonso, Luciano (2000). «El Estado social administrativo: algunas reflexiones sobre la «crisis» de las prestaciones y los servicios públicos». Revista de Administración Pública, 153: 217-249

-. (2014). Lecciones de Derecho Administrativo. Valencia: Editorial Tirant Lo Blanch.

Pegoraro, Lucio (2011). «Existe un derecho a una buena administración». En: Carmen María Ávila Rodríguez y Francisco Gutiérrez Rodríguez, Francisco (Coordinadores), El derecho a una buena administración y la ética pública. Valencia: Tirant lo Blanch.

Ponce SolÉ, Juli (2001). Deber de buena administración y derecho al procedimiento administrativo debido: las bases constitucionales del procedimiento administrativo y del ejercicio de la discrecionalidad. Madrid: Lex Nova.

RodríGUEZ-Arana, Jaime (2014). «La buena administración como principio y como derecho fundamental en Europa». Revista de Derecho y Ciencias Sociales de Colombia, 6: 23-56.

-. (2013). El derecho a una buena administración para los ciudadanos: un modelo global de administración. La Coruña: NetBiblo.

Schmidt-Assmann, Eberhard (2003). La teoría general del derecho administrativo como sistema: objeto y fundamentos de la construcción sistemática. Madrid: Marcial Pons.

Soто Kloss, Eduardo (2012). Derecho Administrativo: temas fundamentales. Santiago: Abeledo Perrot, Legal Publishing.

Tomás MALLÉN, Beatriz (2004). El derecho fundamental a una buena administración. Madrid: Instituto Nacional de Administración Pública.

ViÑuales Ferreiro, Susana (2014). «La constitucionalización del derecho a una buena administración en la Unión Europea: ¿nuevas garantías para la protección de los derechos en el procedimiento administrativo?». Revista de Derecho de la Unión Europea, 27 y 28: 321-340.

WAHL, Rainer (2013). Los últimos 50 años del derecho administrativo alemán. Madrid: Marcial Pons. 


\section{Sobre la autora}

Izaskun Linazasoro Espinoza es abogada, licenciada en Ciencias Jurídicas y Sociales de la Universidad de Chile y diplomada en Regulación y Derecho Público del Centro de la Regulación y Competencia de la Universidad de Chile. Ayudante ad honorem de las cátedras de Derecho Administrativo y Responsabilidad del Estado impartidas en la Facultad de Derecho de la Universidad de Chile, por el profesor Luis Cordero Vega. Su correo electrónico es izaskun.linazasoro@gmail.com. 
